University of Nebraska - Lincoln

DigitalCommons@University of Nebraska - Lincoln

USDA Wildlife Services - Staff Publications

U.S. Department of Agriculture: Animal and Plant Health Inspection Service

2012

\title{
Exploiting Antipredator Behavior in White-Tailed Deer for Resource Protection
}

Bradley F. Blackwell

U.S. Department of Agriculture, bradley.f.blackwell@aphis.usda.gov

Thomas W. Seamans

USDA/APHIS/WS National Wildlife Research Center, thomas.w.seamans@aphis.usda.gov

Laura A. Tyson

U.S. Department of Agriculture

Jerrold L. Belant

Mississippi State University

Kurt C. VerCauteren

USDA-APHIS-Wildlife Services, kurt.c.vercauteren@usda.gov

Follow this and additional works at: https://digitalcommons.unl.edu/icwdm_usdanwrc

Blackwell, Bradley F.; Seamans, Thomas W.; Tyson, Laura A.; Belant, Jerrold L.; and VerCauteren, Kurt C., "Exploiting Antipredator Behavior in White-Tailed Deer for Resource Protection" (2012). USDA Wildlife Services - Staff Publications. 1079.

https://digitalcommons.unl.edu/icwdm_usdanwrc/1079

This Article is brought to you for free and open access by the U.S. Department of Agriculture: Animal and Plant Health Inspection Service at DigitalCommons@University of Nebraska - Lincoln. It has been accepted for inclusion in USDA Wildlife Services - Staff Publications by an authorized administrator of DigitalCommons@University of Nebraska - Lincoln. 


\title{
Exploiting Antipredator Behavior in White-Tailed Deer for Resource Protection
}

\author{
BRADLEY F. BLACKWELL, ${ }^{\mathbf{1}}$ United States Department of Agriculture, Animal and Plant Health Inspection Service, Wildlife Services, \\ National Wildlife Research Center, Obio Field Station, 6100 Columbus Avenue, Sandusky, OH 44870, USA \\ THOMAS W. SEAMANS, United States Department of Agriculture, Animal and Plant Health Inspection Service, Wildife Services, \\ National Wildlife Research Center, Obio Field Station, 6100 Columbus Avenue, Sandusky, OH 44870, USA \\ LAURA A. TYSON, United States Department of Agriculture, Animal and Plant Health Inspection Service, Wildife Services, \\ National Wildlife Research Center, Obio Field Station, 6100 Columbus Avenue, Sandusky, OH 44870, USA \\ JERROLD L. BELANT, Center for Resolving Human-Wildife Conflicts, Department of Wildlife, Fisheries, and Aquaculture, \\ Mississippi State University, Mississippi State, MS 39762, USA \\ KURT C. VerCAUTEREN, United States Department of Agriculture, Animal and Plant Health Inspection Service, Wildlife Services, \\ National Wildlife Research Center, 4101 LaPorte Avenue, Fort Collins, CO 80521, USA
}

\begin{abstract}
Effects of visual obstruction on white-tailed deer (Odocoileus virginianus) include enhanced vigilance and flight-initiation distances. Prior work suggests that artificial visual barriers might enhance perceived risk of predation to deer. During 2008-2010 at the National Aeronautics and Space Administration's Plum Brook Station (Erie County, $\mathrm{OH}$ ), we tested the hypotheses that visual obstruction of winter feeding stations would result in fewer white-tailed deer visiting treatment stations and increased vigilance exhibited relative to deer using control stations. When feeding stations were bounded on 3 sides by a 22.5-m-long, 1.5-m-high, continuous, polyethylene visual barrier (including a 5-m opening on the fourth side), and offset from the food resource by $22.5 \mathrm{~m}$, we observed no differences in deer use or vigilance compared with control stations (4.5- $\mathrm{cm}$ mesh, snow fencing only). In a second experiment, feeding stations bounded by individual, 1.5-m-high, polyethylene visual barriers, positioned on 3 sides only and offset from the food resource by only $7.6 \mathrm{~m}$ each, were characterized by 1 ) fewer deer, 2) increased alert behavior (e.g., head held above horizontal, ears erect, body posture noticeably stiff and animal paused, directed attention, tail flagging, or fleeing) by deer using the stations, and 3) fewer deer using stations at night, relative to control stations. Visual barriers offset at most by $7.6 \mathrm{~m}$ from a food resource (e.g., crops), or located randomly within target areas frequented by deer can offer temporary and easily manipulated means of diminishing deer use of resources on unfenced General Aviation airports or depredation of agricultural crops, and ready integration with other management methods. Published 2012. This article is a U.S. Government work and is in the public domain in the USA.
\end{abstract}

KEY WORDS agriculture, airport, antipredator behavior, foraging, Odocoileus virginianus, vigilance, visual barrier, white-tailed deer.

In North America, successful conservation of deer (Cervidae) populations and habitats has led to overabundance of some species, particularly white-tailed deer (Odocoileus virginianus; McCabe and McCabe 1997). Deer overabundance has resulted in habitat degradation (Waller and Alverson 1997), agricultural damage, heightened levels of zoonoses (Conover et al. 1995, VerCauteren et al. 2007), property damage (Conover et al. 1995, Conover 1997), and an increasing frequency of deer-vehicle collisions (Conover et al. 1995, D'Angelo et al. 2004, Dolbeer and Wright 2008, Blackwell and Seamans 2009). Planned reductions in species populations to reduce hazards or damage to property and habitats (i.e., in addition to scheduled hunting seasons) are

Received: 30 January 2012; Accepted: 15 April 2012

Published: 10 August 2012

${ }^{1}$ E-mail: bradley.f.blackwell@aphis.usda.gov subject to public perspectives on the value of wildlife (Blackwell et al. 2003, Fulton et al. 2004, Runge et al. 2009).

Further, physical exclusion of deer from critical areas or anthropogenic resources, though generally acceptable and effective, is costly (VerCauteren et al. 2006a). Decisions to exclude deer via fencing must be weighed against immediate and future costs associated with damage, and installation and maintenance costs of fencing (VerCauteren et al. $2006 a, b)$. In some cases, such as at airports, deer pose a substantial safety hazard (DeVault et al. 2008, 2011; Dolbeer and Wright 2008; Biondi et al. 2011), but funding to exclude deer from air operations areas (AOAs; see Federal Aviation Administration [FAA] 2009a) via fencing is often unavailable for many smaller airports (e.g., General Aviation airports; DeVault et al. 2008, Dolbeer et al. 2008).

Typically, integrating habitat management with exclusion and lethal control will reduce aviation hazards posed by deer 
(see Cleary and Dolbeer 2005). However, given funding constraints at many airports, we questioned whether property boundaries or existing fencing $<1.8 \mathrm{~m}$ high (i.e., surmountable by deer; see VerCauteren et al. 2010) could be enhanced to elevate vigilance levels of deer approaching the area. Specifically, because vigilance is generally correlated with the perceived risk of predation posed to deer and directly affects other behaviors (e.g., foraging), the opportunity exists to exploit antipredation behavior to reduce use of a particular habitat, be it an AOA or an agricultural setting.

Perception of risk is a key component to such management, because animals must balance the need to forage, rest, and reproduce with the associated risk of predation during each activity (Lima and Dill 1990, Illius and Fitzgibbon 1994, Brown 1999, Lima and Bednekoff 1999). In numerous ungulate species, time spent vigilant in response to potential risk increases as distance to visual obstruction (i.e., cover characteristics that might conceal a predator) decreases (e.g., Underwood 1982, Isvaran 2007, Moser et al. 2008). Mule deer (O. hemionus) exhibited higher levels of vigilance at forest edges than in open and forest areas (Altendorf et al. 2001). Similarly, LaGory (1986) noted that vigilance by white-tailed deer increased with height of cover vegetation. LaGory (1987) found that white-tailed deer exhibited decreased alert and flight behaviors with increased distance from potential threats (see also Lingle and Wilson 2001). However, white-tailed deer might flee in dense vegetation, even when a predator is at considerable distance, likely because of loss of visual contact with the predator (LaGory 1987). Further, DePerno et al. (2003) reported that foraging habitat for white-tailed deer (across gender and seasons) comprised a lower proportion of visual obstruction within overall deer habitat, and was farther from visual obstruction than were bedding areas (where cover is advantageous; see also Huot 1974).

The effect of distance to obstruction on vigilance and selection of foraging areas by white-tailed deer (as well as other ungulate species) suggests that resource use could be altered via visual barriers to enhance perceived threats of predation. Here, the application is intended as an interim method to be followed by exclusion, and as a potential approach to be integrated with exclusion and other management practices. We note that our question, in the context of application, is not novel. Gallagher et al. (2003) constructed a visual barrier around feeding stations and reported a reduction in consumption of whole-kernel corn and in numbers of free-ranging deer entering the stations. Their findings are encouraging, but the experimental design included a relatively small sample size, lacked independence of controls, and the potential confounding effects on deer vigilance and foraging due to the small inside area of the fenced station $(10 \mathrm{~m} \times 10 \mathrm{~m})$ were unclear.

We tested the hypotheses that visual obstruction of feeding stations would result in fewer white-tailed deer within treatment stations and increased vigilance behavior exhibited by deer visiting treatment stations versus those using control stations. Our objectives were to establish a baseline of daily consumption rates of whole-kernel corn (the attractant) at feeding stations during winter, and then to quantify an index of deer use and vigilance behavior after introduction of visual barriers at randomly selected stations.

\section{STUDY AREA}

We conducted the study on the 2,200-ha National Aeronautics and Space Administration's Plum Brook Station (PBS; Erie County, OH; $41^{\circ} 22^{\prime} \mathrm{N}, 82^{\circ} 41^{\prime} \mathrm{W}$ ). Habitat within PBS differed from the surrounding exurban development, comprising canopy-dogwood (Cornus spp.), old field and grasslands, open woodlands, and mixedhardwood forests interspersed by abandoned and actively used structures relating to National Aeronautics and Space Administration and prior operations, and paved roads that circled and bisected the station. The deer population on PBS during our study ranged from approximately 43 deer $/ \mathrm{km}^{2}$ (2009) to approximately $23 \mathrm{deer} / \mathrm{km}^{2}$ (2010; Robert Ford, Ohio Department of Natural Resources, Division of Wildlife, and Tara Baranowski, United States Department of Agriculture, Wildlife Services, unpublished report) and, because of openings within the fence line, was considered an open population. Also, coyotes (Canis latrans) bred on PBS (T. W. Seamans and B. F. Blackwell, personal observations) and represented a potential predation risk, primarily to young, injured, and diseased deer (Gehrt 2006, Saafeld and Ditchkoff 2007).

\section{METHODS}

The PBS deer population is hunted on preselected days during November and, in some years, during December and January. We allowed $\geq 2$ weeks after the last hunt to begin data collection. Our methods were approved by the National Wildlife Research Center Institutional Animal Care and Use Committee (Protocol no. 1606).

\section{Experiment 1}

Design and data collection.-Our first experiment was designed to discern the effects of a nearly continuous visual barrier that surrounded a feeding station on deer use and vigilance. The feeding station (hereafter, "station") comprised $0.2 \mathrm{ha}$, exceeding by a factor of $>20$ that described by Gallagher et al. (2003). During December 2008, we established 10 stations, with $\geq 1-\mathrm{km}$ separation; all stations were located $<46 \mathrm{~m}$ from a paved road. Based on DNA sampling from the PBS deer "population" and suspected movements by individuals (Belant et al. 2007), we considered these stations independent. Also, we assumed that all stations would be exposed to similar levels of vehicle disturbance.

At each station we installed a 3-sided, 1.5-m-high $\times$ 45.0-m-long (per side) orange, plastic, $4.5-\mathrm{cm}$ mesh, snow fence attached to $1.8-\mathrm{m}$ metal fence posts. On the fourth side (i.e., the open side of the feeding station and that faced the road), we extended the snow fence $20 \mathrm{~m}$ from each corner, leaving a 5-m opening (Fig. 1a). Each station was surrounded by grass and sparse shrubs in a perimeter $\geq 5 \mathrm{~m}$ wide along the outside of the fence. Beyond this perimeter, 
Experiment 1 (2009)
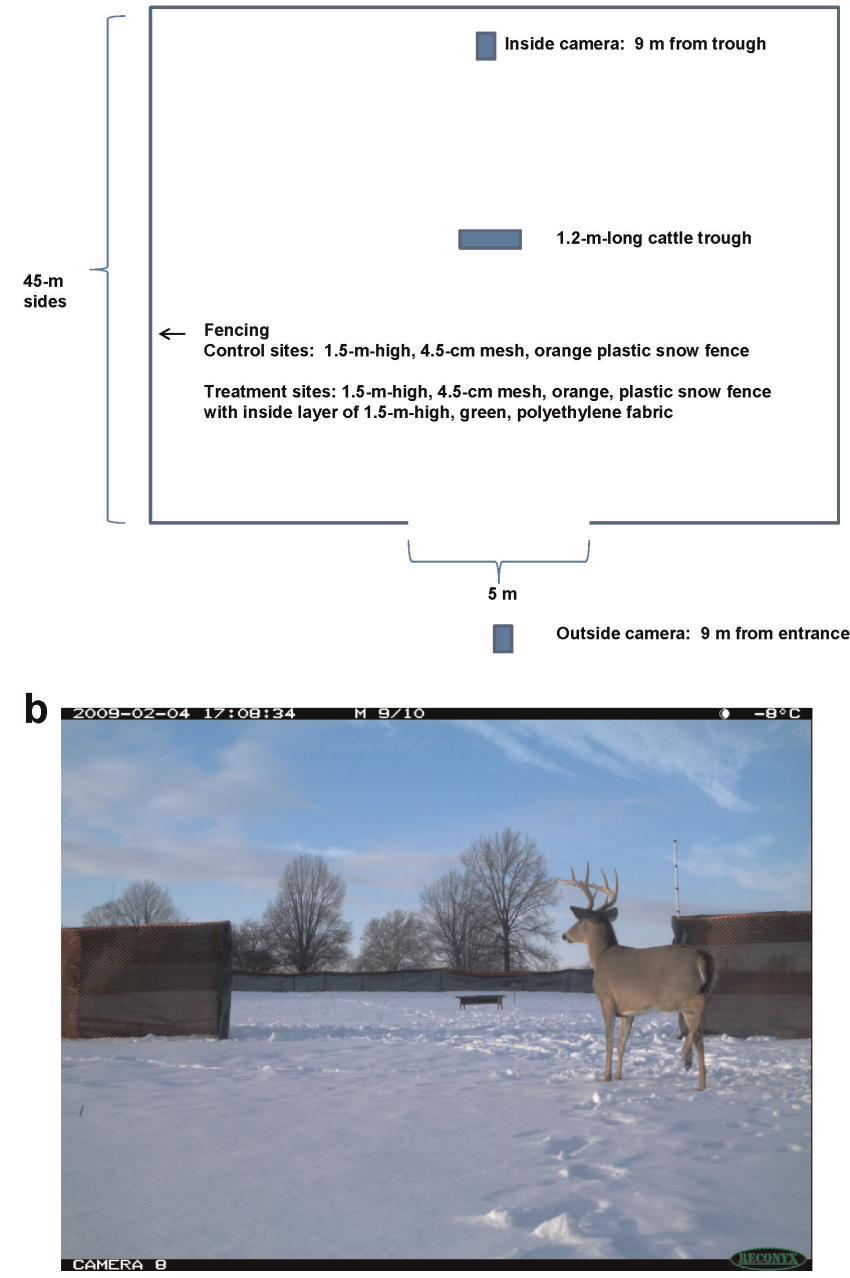

Figure 1. (a) Feeding station design during a winter 2009 experiment in Erie County, Ohio, USA $\left(41^{\circ} 22^{\prime} \mathrm{N}, 82^{\circ} 41^{\prime} \mathrm{W}\right)$ to assess effects of visual barriers on white-tailed deer use of a food resource (whole-kernel corn). (b) Example of 0.2-ha feeding station bounded by snow fencing and green, polyethylene fabric used as the visual barrier.

vegetation at all stations transitioned to a greater density of shrubs and trees within $100 \mathrm{~m}$.

We placed a 1.2-m-long feed trough centrally within each feeding station, about $22.5 \mathrm{~m}$ from each side, half the approximate $50-\mathrm{m}$ distance to visual obstruction reported at winter feeding areas by DePerno et al. (2003). Beginning 23 January 2009, we supplied each trough with whole-kernel corn, and monitored corn consumption by fitting each trough with a metal indicator plate at each end; the plates were calibrated in $4.5-\mathrm{kg}(10-\mathrm{lb})$ intervals for corn weight in the trough (see Belant et al. 1997). We added corn as necessary to maintain a constant food supply.

To record indices of the number of individuals at stations (i.e., deer along the fence, at the entrance, or within the fencing) and associated alert behaviors, we positioned 2 remotely activated, digital cameras with infrared flash (RapidFire $^{\mathrm{TM}}$, Reconyx, Inc., Holmen, WI), one covering the front and entry of each station (with view of the trough and rear of the enclosure) and the other at the rear of the station, centered on the trough and facing the entrance (Fig. 1a). We adjusted cameras such that when an animal triggered the passive, infrared motion detector, 10 date- and time-stamped photographs were recorded over $10 \mathrm{~s}$. We set cameras to a 5-min interval between series of 10 photographs. We considered that any bias due to camera presence was distributed equally across stations.

We recognized that by providing a high-energy food resource during an energy-demanding period, as well as in the context of novel situation, that we likely created an artificial mix of age and sexes, thereby enhancing the likelihood of alert behaviors. Therefore, we recorded not only the number of individuals that showed general alert behavior (e.g., ears erect, neck extended forward), but also those individuals that exhibited heightened alert (head held above the horizontal, ears erect, body posture noticeably stiff and animal paused, directed attention, tail flagging, or fleeing; see LaGory 1986, Altendorf et al. 2001, Lingle and Wilson 2001, Childress and Lung 2003).

Our pretreatment period extended from 23 January through 3 February, which allowed deer to establish consistent use of all stations. On 3 and 4 February, we fitted 5 stations, randomly selected, with a $1.5-\mathrm{m}$-high, dark-green, polyethylene fabric (privacy screen; Volm, Inc., Antigo, WI) secured to the snow fencing and fence posts on the side interior to the station (Fig. 1b). Neither the snow fence (control stations) nor the combination of snow fence and visual barrier (treatment stations) were intended to serve as physical barriers to entry, because deer readily jumped these fences (see VerCauteren et al. 2010). In addition, we considered as negligible the possibility that snow fencing around control stations posed enough of a visual barrier to mask any effect at treatment stations. Specifically, humans could readily detect movement on the opposite side of the fence, and similar experimental designs using the same type of snow fence were previously used on PBS (Seamans et al. 2002, Seamans and VerCauteren 2006). We monitored snow depth (via ruler), corn consumption by deer, deer numbers, and alert behaviors exhibited by deer through 12 February 2009, when our sites were destroyed by a wind storm.

Experiment 1 analysis. - Because of the potential effect of novelty of the visual barriers at treatment stations, we based our analysis on data collected (at all stations) $\geq 3$ days after barrier installation, including data for deer numbers and alert behaviors from 6 through 12 February 2009. With regard to the 2 treatment stations for which barrier installation was not completed until 4 February 2009, we omitted from our analysis observations from those stations made on 6 February.

The 2 camera placements per station overlapped field of views; thus, on some occasions we recorded the same individual(s) with both cameras. We, therefore, used data from the inside camera, because it consistently recorded more individuals per photograph at each station. For each photograph by station, we summarized the number of individuals at the station, number of those individuals actually inside the fenced area (i.e., the forage group), and general versus heightened alert behaviors, as described above. We then calculated daily means relative to station and an index of 
ambient light energy. Our calculation of means was intended as a partial and initial control for possible correlations associated with repeated observations of the same individuals at a station within short time periods. We also considered that ambient light conditions could be correlated with levels of vigilance. We defined our ambient light index relative to the bounds of light-energy measurements recorded at 15-min intervals using a WeatherHawk 916 weather station (Logan, UT) installed on PBS near the feeding stations. During our study, we measured approximately $11 \mathrm{hr}$ of light energy/24-hr period. In addition, we recognize that our estimates of total number of deer within a field of view could be biased by dark conditions. However, we considered this potential bias as consistent across all metrics for a particular station and across stations. Thus, our scores for individuals relative to their alert status should not be biased relative to our ability to detect deer in photographs taken at night.

Individuals that exhibited a heightened level of alert behavior were typically fewer than or equal to the number that exhibited a general state of alert. We used the ratio of individuals that showed heightened versus general alert behaviors (i.e., alert ratio) as our response variable for vigilance. Because the number of deer that used our stations varied, individuals frequently exhibited a general state of alert, and not all individuals exhibiting heightened alert were inside the fenced area, this ratio allowed us to standardize our vigilance metric to avoid bias associated with absolute numbers of vigilant deer.

We used a mixed linear model, repeated-measures analysis with date as the repeated-measures factor, the KenwardRogers adjustment to degrees of freedom, an autoregressive correlation structure, and Type III sums of squares (Mixed Procedure, SAS ver. 8.2; SAS Institute, Cary, NC) to evaluate the difference between treatments in effect on forage group size and alert ratio. We added 1 to all values for forage group size and used a square-root transformation to normalize these data. We also considered our light index (entered as a class variable in analyses on forage group and alert ratio) and forage group (vigilance analysis) as candidate fixed and random effects, respectively. We considered the potential effect of forage group because group size can have an inverse effect on individual vigilance levels (LaGory 1986, 1987; see, however, Elgar 1989). We did not use the total number of deer within view, because this metric often included individuals or pairs along the fence and not associated with a larger group. We included an effect in our model only if the probability associated with the least-squares (LS) mean for that effect was $\leq 0.10$. Finally, we assessed assumptions of normality by treatment using model residuals, and evaluated differences in LS means $(\alpha=0.05)$ for the model class variables.

\section{Experiment 2}

Design and data collection.-We continued our focus on effects of a visual barrier on deer foraging and vigilance, but in the context of an approach that could be more easily integrated at airports or in agricultural settings with other methods to deter deer. Because we did not intend to make comparisons between experiments, we used the same control and treatment stations from Experiment 1. We began pretreatment on 19 January 2010 by placing 31.8 -m fence posts along a $7.6-\mathrm{m}$ distance perpendicular to, and $7.6 \mathrm{~m}$ from, each end and the rear side of a feed trough positioned centrally within a station. However, unlike Experiment 1 or work by Gallagher et al. (2003), approximately $3.8 \mathrm{~m}$ separated the last or end fence post in the 2 rear corners of the station. Further, the station provided $>15 \mathrm{~m}$ between fences. Also, the side of the feed trough that faced the road was left open. At all stations, we positioned a single remotely activated, digital camera on the open or road side of the station, facing the trough and offset from the center of the trough by $9 \mathrm{~m}$. We observed the same protocol as that in Experiment 1 with respect to pretreatment data collection during the organized hunt days on PBS and the start of the formal experiment.

On 27 January, we fitted 5 treatment stations with 3 individual, 7.6-m-long, 1.5-m-high fences composed of the orange plastic snow fence covered by the dark-green polyethylene fabric, both used in Experiment 1. As noted

a

Experiment 2 (2010)

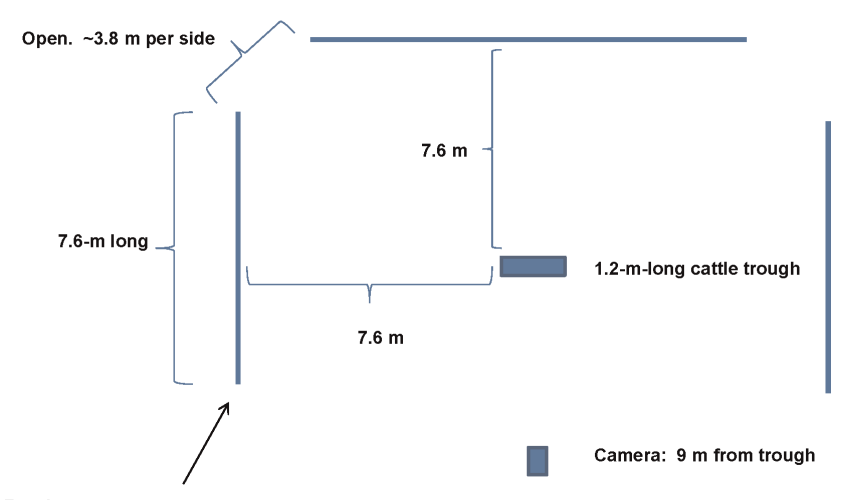

Fencing

Control sites: $1.8-\mathrm{m}$-high fence posts only

Treatment sites: $1.8-\mathrm{m}$-high posts with $1.5-\mathrm{m}-\mathrm{high}, 4.5-\mathrm{cm}$ mesh, orange, plastic snow fence and inside layer of $1.5-\mathrm{m}$, green polyethylene fabric

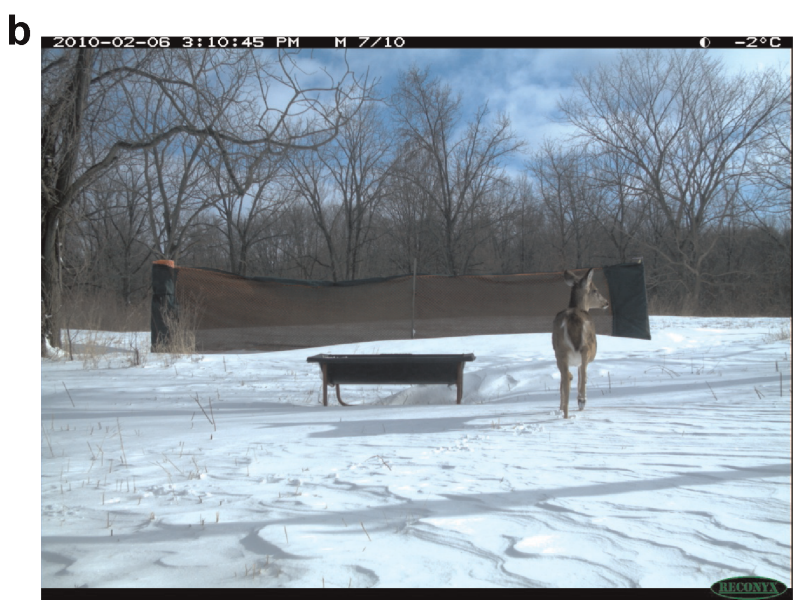

Figure 2. (a) Feeding station design during a winter 2010 experiment in Erie County, Ohio, USA $\left(41^{\circ} 22^{\prime} \mathrm{N}, 82^{\circ} 41^{\prime} \mathrm{W}\right)$ to assess effects of visual barriers on white-tailed deer use of a food resource (whole-kernel corn). (b) Example of 0.02-ha feeding station bounded by snow fencing and green polyethylene fabric used as the visual barrier. 
above, the fourth side of the station was left open to the road (Fig. 2a,b). This design encompassed approximately 0.02 ha (10\% of the area used in Experiment 1) but allowed deer greater visibility of conditions outside the station. In contrast, we maintained control stations as described for the pretreatment period, with no snow fencing or visual barrier. We monitored snow conditions, corn consumption, deer numbers and alert behaviors (as described for Experiment 1) through 8 February 2010.

Experiment 2 analysis. - We included in our analyses data from 1 through 8 February 2010. Relative to discerning treatment effects on forage group size, we followed the same analytical approach for Experiment 2 as described for Experiment 1. However, we could not normalize our data for alert ratio; thus, we evaluated the difference between treatments by using the Wilcoxon 2-sample test, normal approximation, and 2-sided probability distribution $(\alpha=0.025)$. Given our calculation of mean values for the number of individuals showing general or heightened alert, which reduced the number of observations per station and potential effect of auto-correlated data, we included this analysis with this caveat. We followed the same approach to examine the potential effect of the light index.

\section{RESULTS}

\section{Experiment 1}

Air temperature during our 2009 experiment ranged from $-26.5^{\circ} \mathrm{C}$ to $16.6^{\circ} \mathrm{C}\left(\bar{x}\right.$ quarter-hr temp $=-0.5^{\circ} \mathrm{C}$, $\mathrm{SE}=-8.5^{\circ}$ ). Snow depth reached $30 \mathrm{~cm}$ on 29 January, decreased to $21 \mathrm{~cm}$ by 9 February, and melted entirely by 10 February.

The number of deer at stations was similar between treatments (Table 1). Forage group size was similar between treatments (LS means: estimate $=-0.05, \quad \mathrm{SE}=0.04$, $\mathrm{df}=79.8, \quad t=-1.17, P=0.25$; Table 1$)$, but smaller at night (LS means: estimate $=-0.10, \mathrm{SE}=0.04, \mathrm{df}=$ 54.7, $t=-2.86, P<0.01$; Table 1$)$. Group size did not influence vigilance behaviors, and was excluded from our final vigilance model. Differences in behavioral metrics between treatments were negligible (Table 1), and we found no difference in alert ratio between treatments (LS means: estimate $=0.10, \mathrm{SE}=0.05, \mathrm{df}=86.1, t=1.85$, $P=0.07$, nor an effect due to ambient light conditions (LS means: estimate $=-0.02, \mathrm{SE}=0.04, \mathrm{df}=56.0$, $t=-0.46, P=0.65)$.

\section{Experiment 2}

Air temperature during our 2010 experiment ranged from $-21.7^{\circ} \mathrm{C}$ to $2.3^{\circ} \mathrm{C}\left(\bar{x}=-6.5^{\circ} \mathrm{C}, \mathrm{SE}=-12.0^{\circ} \mathrm{C}\right)$. Snow depth was $<5 \mathrm{~cm}$ until 8 February (the last day of the experiment), when a maximum depth of $15 \mathrm{~cm}$ was recorded.

Unlike Experiment 1 during the treatment period, we noted $35 \%$ more deer at control versus treatment stations and across light conditions (Table 1). Forage group size was about 25\% less at treatment stations (LS means: estimate $=-0.14, \quad \mathrm{SE}=0.03, \mathrm{df}=135.0, \quad t=-5.38$, $P<0.01$ ), and at night (LS means: estimate $=-0.10$, $\mathrm{SE}=0.02, \mathrm{df}=100.0, t=-5.89, P<0.01$; Table 1$)$. Further, alert ratio was about $29 \%$ greater at treatment stations (sum of scores $=13,217.0$, expected $=11,707.5$, $\mathrm{SE}=477.7, \quad P<0.01$ ) than control stations (sum of scores $=11,536.0, \quad$ expected $=13,045.5, \quad \mathrm{SE}=477.7)$, and similar between light (sum of scores $=11,125.0$, expected $=11,819.0, \quad \mathrm{SE}=477.9$ ) and dark periods (sum of scores $=13,628.0$, expected $=12,934.0, \mathrm{SE}=477.9$, $P=0.15)$. However, forage group size was negatively correlated with the alert ratio $(N=222, \rho=-0.22$, $P<0.01)$.

\section{DISCUSSION}

In the context of winter conditions and provision of a highenergy food source (whole-kernel corn), we demonstrated that distance to an anthropogenic visual barrier can affect perceived risk by white-tailed deer. We discuss our findings relative to deer numbers at feeding stations and vigilance, but also with respect to inherent caveats of the study design. We then extend our findings to the context of exploiting predation risk to reduce deer use of sensitive areas and depredation of resources.

Over the 10 days of Experiment 1, we showed that application of a nearly continuous visual barrier that created a

Table 1. Use of 10 feeding stations, located in Erie County, Ohio, USA $\left(41^{\circ} 22^{\prime} \mathrm{N}, 82^{\circ} 41^{\prime} \mathrm{W}\right)$, by white-tailed deer during the winters of 2009 (Experiment 1 , 10-day period) and 2010 (Experiment 2, 12-day period), in which effects of visual barriers on deer use and vigilance behaviors were assessed. Metrics represent average deer numbers relative to date, station, and light-energy levels recorded on site. See text for description of experimental designs and definitions of alert behaviors. Differences in least squares means, significant at $\alpha=0.05$, for deer numbers inside fencing, between Control and Treatment, and within experiment, are indicated as $\dagger$.

\begin{tabular}{|c|c|c|c|c|c|c|c|c|c|c|c|c|c|c|c|c|}
\hline \multirow[b]{3}{*}{ Experiment } & \multicolumn{16}{|c|}{ Ambient conditions } \\
\hline & \multicolumn{8}{|c|}{ Light } & \multicolumn{8}{|c|}{ Dark } \\
\hline & $\begin{array}{c}\text { No./ } \\
\text { station }\end{array}$ & $\mathrm{SE}$ & $\begin{array}{c}\text { No. } \\
\text { inside } \\
\text { fencing }\end{array}$ & $\mathrm{SE}$ & $\begin{array}{l}\text { No. } \\
\text { alert }\end{array}$ & SE & $\begin{array}{c}\text { No. } \\
\begin{array}{c}\text { heightened } \\
\text { alert }\end{array}\end{array}$ & SE & $\begin{array}{c}\text { No./ } \\
\text { station }\end{array}$ & $\mathrm{SE}$ & $\begin{array}{c}\text { No. } \\
\text { inside } \\
\text { fencing }\end{array}$ & $\mathrm{SE}$ & $\begin{array}{l}\text { No. } \\
\text { alert }\end{array}$ & SE & $\begin{array}{c}\text { No. } \\
\begin{array}{c}\text { heightened } \\
\text { alert }\end{array}\end{array}$ & $\mathrm{SE}$ \\
\hline \multicolumn{17}{|l|}{ Experiment 1} \\
\hline Control & 2.5 & 0.8 & 2.3 & 0.7 & 1.7 & 0.7 & 0.6 & 0.4 & 2.0 & 0.9 & 1.9 & 0.8 & 1.4 & 0.5 & 0.5 & 0.3 \\
\hline Treatment & 2.7 & 1.1 & 2.1 & 0.8 & 2.0 & 0.6 & 0.9 & 0.6 & 2.0 & 0.8 & 1.7 & 0.6 & 1.4 & 0.6 & 0.6 & 0.4 \\
\hline \multicolumn{17}{|l|}{ Experiment 2} \\
\hline Control & 2.8 & 0.9 & 2.6 & $0.8 \dagger$ & 2.0 & 0.7 & 0.4 & 0.3 & 2.2 & 0.6 & 2.2 & $0.6 \dagger$ & 1.6 & 0.5 & 0.3 & 0.2 \\
\hline Treatment & 2.1 & 0.6 & 2.0 & $0.6 \dagger$ & 1.6 & 0.5 & 0.4 & 0.2 & 1.6 & 0.4 & 1.6 & $0.4 \dagger$ & 1.2 & 0.3 & 0.3 & 0.2 \\
\hline
\end{tabular}


0.2-ha area around a centrally located food resource did not affect the number of deer exploiting the resource or their vigilance. Notably, station dimensions afforded approximately $45 \mathrm{~m}$ between fences, about half the distance-to-visual-obstruction noted by DePerno et al. (2003) for foraging habitats used by white-tailed deer. Still, we suggest that findings of no effect of the visual barrier on deer numbers or vigilance are consistent with those of LaGory (1987) relative to the obstructive effect of vegetation on vigilance in white-tailed deer. Specifically, open habitat within stations and the $22.5-\mathrm{m}$ offset of the visual barrier from the food source likely ameliorated any tendency for longer or more frequent scanning periods (see also Lingle and Wilson 2001). Moreover, we suggest that increasing temperatures and decreasing snow depth through this first experiment would likely have lessened energy demands on deer and enhanced risk-aversive behaviors relative to foraging. Still, despite less energetically stressful conditions, we did not see differential use of treated and control stations. We note, however, that our cameras did not allow us to monitor focal individuals for $>10 \mathrm{~s}$.

In contrast, over the 12 days of Experiment 2, when stations were bordered on 3 sides by separate visual barriers that created a 0.02-ha area around the food source and afforded $15 \mathrm{~m}$ between fences, fewer deer entered stations, and deer at treatment stations exhibited increased levels of heightened alert. These findings are consistent with those of LaGory (1986) and Altendorf et al. (2001) relative to deer vigilance while they foraged in densely vegetated habitats versus open habitats. Because we used the same locations and treatment assignments as in Experiment 1 (where no difference was observed in deer numbers between control and treatment stations), we contend that reduction in use of treatment stations during Experiment 2 is a result of enhanced perceived risk posed by the position of the visual barriers. We caution, however, that the negative relationship between alert ratio and forage group size could be a product of competition for access to food (see Elgar 1989).

Given that wildlife fencing is designed to protect a resource, evaluations of fencing methods are benefitted by metrics of whether the resource is, indeed, protected. A factor that detracted from discerning more broadly the effects of visual barriers on deer use of stations was our inability to accurately standardize corn consumption relative to foraging pressure (i.e., individual consumption rates). Specifically, a metric of relative consumption between control and treatment stations concurrent with behavioral metrics would have yielded improved understanding of whether, or how, deer compensate for perceived risk (e.g., via compensatory vigilance and foraging behaviors, or "multitasking"; Fortin et al. 2004a, b; see also Blanchard and Fritz 2007). However, corn consumption by nontarget species, including raccoons (Procyon lotor), fox squirrels (Sciurus niger), mourning doves (Zenaida macroura), Corvids, and Icterids, was prevalent across stations, but not quantifiable. Further, though we could estimate the number of deer within each station, including at the trough, we could not estimate turnover of individuals nor corn removed by an individual or group.
Thus, station-specific foraging by a few hungry individuals that adopt a more risk-prone strategy (Lima 1998) could potentially mask the effects of treatment. Finally, ambient conditions at each station differentially affected consumption and the potential souring of corn because of temperature increases and associated snow melt, as well as the amount of corn present. When corn sours, deer will generally avoid consuming it (B. F. Blackwell and T. W. Seamans, personal observations).

Notably, most research that has examined the effects of manipulation of visual obstruction (absolute or position thereof) on prey species has emphasized understanding antipredator behaviors (Eason and Stamps 1992, Arenz and Leger 1997, Devereux et al. 2004), not exploiting these behaviors to reduce negative interactions with people or other species. However, Franklin and Garrett (1989) demonstrated that visual barriers slow colony expansion and limit site use by black-tailed prairie dogs (Cynomys ludovicianus), which is a nonlethal approach to limiting negative interactions of this species with humans. Still, the report by Gallagher et al. (2003) is, to our knowledge, the only other evaluation of an artificial visual barrier intended to reduce resource use by white-tailed deer.

We contend that visual barriers offer ease of placement and subsequent movement to new locations when protecting a resource. For example, visual barriers could be designed to meet frangibility requirements (FAA 2009b) for use on the AOAs of unfenced airports where deer incursions are frequent, but occur outside the Object Free Area ("an area on the ground centered on a runway, taxiway, or taxilane centerline provided to enhance the safety of aircraft operations...," FAA 1989, Chapter 1:2). In this scenario, and extending our findings in terms of biological effect on an assumed herd of 100 animals, use of visual barriers (without integration of other methods) could, over a short term, decrease potential use of the AOA on average by 25 deer relative to an untreated area. If we assume the area to be protected is a crop, average foraging rates for the remaining individuals could be reduced because of heightened alert status by up to $29 \%$ (see Table 1 ).

Importantly, the greatest level of antipredator behavior should be exhibited in high-risk situations that are brief and infrequent (Lima and Bednekoff 1999; but see also Boersma et al. 2008). Thus, use of visual barriers alone to exploit antipredator behavior in deer, like use of other primary repellents intended to cause immediate disruption in animal activity (e.g., via neophobia, irritation, or pain; Clark 1997), is limited in effectiveness because of potential habituation to stimuli (see Shivik et al. 2003). As such, though our short-term findings show promise for the technique (particularly in that they relate to winter conditions when alternative food sources were few), we do not expect long-term effectiveness of visual barriers against deer without integration of methods that enhance perceived risk. Still, seasonal, cost-effective fence applications can reduce damage to crops such as corn, thus enabling farmers to tolerate higher densities of deer in localized areas (Hildreth et al. 2012). Future research should quantify 
effectiveness over time and scale, including random repositioning of barriers near target resources, both at airports and agricultural settings.

\section{MANAGEMENT IMPLICATIONS}

Temporary fencing (e.g., 1.5-m height and 7.6-m lengths) used to create visual barriers can enhance perceived risk of predation to white-tailed deer and reduce deer use of target resources. Fence sections should be located no more than $7.6 \mathrm{~m}$ from a food resource (e.g., crops), or randomly within target areas frequented by deer (e.g., grassland areas within the AOA of General Aviation airports, but outside the Object Free Area; FAA 1989). We stress that such a management approach should be considered preliminary to permanent deer-proof fencing (DeVault et al. 2008), and that ultimately airports should adopt a zero tolerance for deer (Biondi et al. 2011, DeVault et al. 2011). Visual barriers could also be integrated with permanent fencing and other management tools (e.g., nonlethal harassment, or lethal control; see VerCauteren and Hygnstrom 1998, DeNicola et al. 2000) to reduce crop depredation, particularly at key stages of development.

\section{ACKNOWLEDGMENTS}

Our research was supported by the U.S. Department of Agriculture, Animal and Plant Health Inspection Service, Wildlife Services, National Wildlife Research Center, and the U.S. Federal Aviation Administration under agreement DTFACT-04-X-90003. Author salaries were provided by their respective institutions. We thank B. Buckingham, E. Poggiali, and D. Steyer for assistance during our experiments. T.L. DeVault, P. Kjellander, C.K. Nielsen, and B.E. Washburn provided insightful reviews of earlier versions of this manuscript.

\section{LITERATURE CITED}

Altendorf, K. B., J. W. Laundré, C. A. López González, and J. S. Brown. 2001. Assessing effects of predation risk on foraging behavior of mule deer. Journal of Mammalogy 82:430-439.

Arenz, C. L., and D. W. Leger. 1997. Artificial visual obstruction, antipredator vigilance, and predator detection in the thirteen-lined ground squirrel (Spermophilus tridecemlineatus). Behaviour 134:1101-1114.

Belant, J. L., S. K. Ickes, L. A. Tyson, and T. W. Seamans. 1997. Comparison of four particulate substances as wildlife feeding repellents. Crop Protection 16:439-447.

Belant, J. L., T. W. Seamans, and D. Paetkau. 2007. Genetic tagging freeranging white-tailed deer using hair snares. Ohio Journal of Science 4: $50-56$.

Biondi, K. M., J. L. Belant, J. A. Martin, T. L. DeVault, and G. Wang. 2011. White-tailed deer incidents with U.S. civil aircraft. Wildlife Society Bulletin 35:303-309.

Blackwell, B. F., E. Huszar, G. Linz, and R. A. Dolbeer. 2003. Lethal control of red-winged blackbirds to manage damage to sunflower: an economic evaluation. Journal of Wildlife Management 67:818-828.

Blackwell, B. F., and T. W. Seamans. 2009. Enhancing the perceived threat of vehicle approach to white-tailed deer. Journal of Wildlife Management 73:128-135.

Blanchard, P., and H. Fritz. 2007. Induced or routine vigilance while foraging. Oikos 116:1603-1608.

Boersma, K. S., C. H. Ryer, T. P. Hurst, and S. S. Heppell. 2008. Influences of divergent behavioral strategies upon risk allocation in juvenile flatfishes. Behavioral Ecology and Sociobiology 62:1959-1968.
Brown, J. S. 1999. Vigilance, patch use and habitat selection: foraging under predation risk. Evolutionary Ecology Research 1:49-71.

Childress, M. J., and M. A. Lung. 2003. Predation risk, gender and the group size effect: does elk vigilance depend upon the behavior of conspecifics? Animal Behaviour 66:389-398.

Clark, L. 1997. A review of 117 carbocyclic compounds. Pages 343-352 in J. R. Mason, editor. Repellents in wildlife management. National Wildlife Research Center, Fort Collins, Colorado, USA.

Cleary, E. C., and R. A. Dolbeer. 2005. Wildlife hazard management at airports. Second edition. Federal Aviation Administration, Office of Airport Safety and Standards, Airport, Safety and Compliance Branch, Washington, D.C., USA.

Conover, M. R. 1997. Monetary and intangible valuation of deer in the United States. Wildlife Society Bulletin 25:298-305.

Conover, M. R., W. C. Pitt, K. K. Kessler, T. J. DuBow, and W. A. Sanborn. 1995. Review of human injuries, illnesses, and economic losses caused by wildlife in the United States. Wildlife Society Bulletin 23:407414.

D’Angelo, G. J., R. J. Warren, K. V. Miller, and G. R. Gallagher. 2004. Evaluation of strategies designed to reduce deer-vehicle collisions. Literature review prepared for the Georgia Department of Transportation. University of Georgia, Daniel B. Warnell School of Forest Resources, Athens, USA.

DeNicola, A. J., K. C. VerCauteren, P. D. Curtis, and S. E. Hygnstrom. 2000. Managing white-tailed deer in suburban environments. A technical guide. Cornell Cooperative Extension, the Wildlife Society-Wildlife Damage Management Working Group, and the Northeast Wildlife Damage Research and Outreach Cooperative, Media and Technology Services Resource Center, Ithaca, New York, USA.

DePerno, C. E., J. A. Jenks, and S. L. Griffin. 2003. Multidimensional cover characteristics: is variation in habitat selection related to white-tailed deer sexual segregation? Journal of Mammalogy 84:1316-1329.

DeVault, T. L., J. L. Belant, B. F. Blackwell, and T. W. Seamans. 2011. Interspecific variation in wildlife hazards to aircraft: implications for airport wildlife management. Wildlife Society Bulletin 35:394402.

DeVault, T. L., J. E. Kubel, D. J. Glista, and O. E. Rhodes, Jr. 2008. Mammalian hazards at small airports in Indiana: impact of perimeter fencing. Human-Wildlife Conflicts 2:240-247.

Devereux, C. L., C. U. McKeever, T. G. Benton, and M. J. Whittingham. 2004. The effect of sward height and drainage on common starlings Sturnus vulgaris and northern lapwings Vanellus vanellus foraging in grassland habitats. Ibis 146:115-122.

Dolbeer, R. A., M. J. Begier, and S. E. Wright. 2008. Animal ambush: the challenge of managing wildlife hazards at general aviation airports. Corporate Aviation Safety Seminar 53:1-12.

Dolbeer, R. A., and S. E. Wright. 2008. Wildlife strikes to civil aircraft in the United States, 1990-2007. U. S. Department of Transportation, Federal Aviation Administration, Office of Airport Safety and Standards, Serial Report No. 14, Washington, D.C., USA.

Eason, P. K., and J. A. Stamps. 1992. The effect of visibility on territory size and shape. Behavioral Ecology 3:166-172.

Elgar, M. A. 1989. Predator vigilance and group size in mammals and birds: a critical review of the empirical evidence. Biological Reviews 64: 13-33.

Federal Aviation Administration [FAA]. 1989. Airport design. Advisory Circular, AC 150/5300-13. Airport Safety and Operations Division AA2300, Washington, D.C., USA.

Federal Aviation Administration [FAA]. 2009a. Hazardous wildlife attractants on or near airports. Advisory Circular, AC 150/5200-33B. Airport Safety and Operations Division AA2-300, Washington, D.C., USA.

Federal Aviation Administration [FAA]. 2009b. Frangible connections. Advisory Circular, AC 150/5220-23. Airport Safety and Operations Division AA2-300, Washington, D.C., USA.

Fortin, D., M. S. Boyce, and E. H. Merrill. 2004a. Multitasking by mammalian herbivores: overlapping processes during foraging. Ecology 85:2312-2322.

Fortin, D., M. S. Boyce, E. H. Merrill, and J. M. Fryxell. 2004b. Foraging costs of vigilance in large mammalian herbivores. Oikos 107:172-180.

Franklin, W. L., and M. G. Garrett. 1989. Nonlethal control of prairie dog colony expansion with visual barriers. Wildlife Society Bulletin 17: 426-430. 
Fulton, D. C., K. Skerl, E. M. Shank, and D. W. Lime. 2004. Beliefs and attitudes toward lethal management of deer in Cuyahoga Valley National Park. Wildlife Society Bulletin 32:1166-1176.

Gallagher, G. R., H. A. Keen, and R. H. Prince. 2003. Effectiveness of a perceived solid barrier as an exclusion fence to prevent white-tailed deer damage. Pages 23-28 in K. A. Fagerstone, G. W. Witmer, editors. Proceedings of the 10th Wildlife Damage Management Conference, 6-9 April 2003, Hot Springs, Arkansas, USA.

Gehrt, S. D. 2006. Urban coyote ecology and management. The Cook County, Illinois, Coyote Project. The Ohio State University Extension, FS Bulletin 929, Columbus, USA.

Hildreth, A. M., S. E. Hygnstrom, E. E. Blakenship, and K. C. VerCauteren. 2012. Use of partially fenced fields to reduce deer damage to corn. Wildlife Society Bulletin 36:199-203.

Huot, J. 1974. Winter habitat of white-tailed deer at Thirty-one Mile Lake, Quebec. Canadian Field Naturalist 88:293-301.

Illius, A. W., and C. Fitzgibbon. 1994. Costs of vigilance in foraging ungulates. Animal Behaviour 47:481-484.

Isvaran, K. 2007. Intraspecfic variation in group size in the blackbuck antelope: the roles of habitat structure and forage at different spatial scales. Oecologia 154:435-444.

LaGory, K. E. 1986. Habitat, group size, and the behaviour of white-tailed deer. Behaviour 98:168-179.

LaGory, K. E. 1987. The influence of habitat and group characteristics on the alarm and flight response of white-tailed deer. Animal Behaviour $35: 20-25$.

Lima, S. L. 1998. Nonlethal effects in the ecology of predator-prey interactions-what are the ecological effects of anti-predator decision-making? BioScience 48:25-34.

Lima, S. L., and P. A. Bednekoff. 1999. Temporal variation in danger drives anitpredator behavior: the predation risk allocation hypothesis. American Naturalist 153:649-659.

Lima, S. L., and L. M. Dill. 1990. Behavioral decisions made under the risk of predation: a review and prospectus. Canadian Journal of Zoology 68:619-640.

Lingle, S., and F. Wilson. 2001. Detection and avoidance of predators in white-tailed deer (Odocoileus virginianus) and mule deer (O. hermiounus). Ethology 107:125-147.

McCabe, T. R., and R. E. McCabe. 1997. Recounting whitetails past. Pages 11-26 in W. J. McShea, H. B. Underwood, and J. H. Rappole, editors. The science of overabundance: deer ecology and population management. Smithsonian Institution Press, Washington, D.C., USA.
Moser, B., M. Schütz, and K. E. Hindenland. 2008. Resource selection by roe deer: are windthrow gaps attractive feeding places? Forest Ecology and Management 255:1179-1185.

Runge, M. C., J. R. Sauer, M. L. Avery, B. F. Blackwell, and M. D. Koneff. 2009. Assessing allowable take of migratory birds: black vultures in Virginia. Journal of Wildlife Management 73:556565.

Saafeld, S. T., and S. S. Ditchkoff. 2007. Survival of neonatal white-tailed deer in an exurban population. Journal of Wildlife Management 71:940944.

Seamans, T. W., B. F. Blackwell, and J. D. Cepek. 2002. Coyote hair as an area repellent for white-tailed deer. International Journal of Pest Management 48:301-306.

Seamans, T. W., and K. C. VerCauteren. 2006. Evaluation of ElectroBraid ${ }^{\mathrm{TM}}$ fencing as a white-tailed deer barrier. Wildlife Society Bulletin 34:8-15.

Shivik, J. A., A. Treves, and P. Callahan. 2003. Nonlethal techniques for managing predation: primary and secondary repellents. Conservation Biology 17:1531-1537.

Underwood, R. 1982. Vigilance behavior in grazing African antelopes. Behavior 79:81-107.

VerCauteren, K. C., and S. Hygnstrom. 1998. Effects of agricultural activities and hunting on home ranges of female white-tailed deer. Journal of Wildlife Management 62:280-285.

VerCauteren, K. C., M. J. Lavelle, and S. Hygnstrom. 2006a. Fences and deer-damage management: a review of designs and efficacy. Wildlife Society Bulletin 34:191-200.

VerCauteren, K. C., M. J. Lavelle, and S. Hygnstrom. 2006b. A simulation model for determining cost-effectiveness of fences for reducing deer damage. Wildlife Society Bulletin 34:16-22.

VerCauteren, K. C., M. J. Lavelle, N. W. Seward, J. W. Fischer, and G. E. Phillips. 2007. Fence-line contact between wild and farmed white-tailed deer in Michigan: potential for disease transmission. Journal of Wildlife Management 71:1603-1606.

VerCauteren, K. C., T. R. VanDeelen, M. J. Lavelle, and W. H. Hall. 2010. Assessment of abilities of white-tailed deer to jump fences. Journal of Wildlife Management 74:1378-1381.

Waller, D. M., and W. S. Alverson. 1997. The white-tailed deer: a keystone herbivore. Wildlife Society Bulletin 25:217-226.

Associate Editor: Hewison. 